\title{
Performa Anak Hasil Persilangan antara Induk Sapi PO dengan Bangsa Pejantan yang Berbeda di Wilayah Inseminasi Buatan (IB) di Kecamatan Terbanggi Besar Kabupaten Lampung Tengah
}

\author{
M. D. I. Hamdani ${ }^{1}$, Sulastri ${ }^{1}$, \& T. Rumiyani ${ }^{2}$ \\ ${ }^{1}$ Jurusan Peternakan, Fakultas Pertanian, Universitas Lampung \\ Jl. Soemantri Brodjonegoro No.1 Gedong Meneng, Rajabasa, Bandar Lampung 35415 \\ ${ }^{2}$ Jurusan Peternakan, Politeknik Negeri Lampung \\ Jln. Soekarno Hatta No. 10 Bandar Lampung 35415 \\ Email : dima.iqbal@fp.unila.ac.id \\ (Diterima : 18 Februari 2020; Disetujui : 21 September 2020)
}

\begin{abstract}
The research investigates to know performance of calf from Crossing between Peranakan Ongole (PO) dams with some of the bull at one years age. Located of research in Terbanggi Besar District, Central Lampung Regency. This research was doing in May until August 2018. Material of research are 30 head PO Cattle, 30 head Simmental $><P O ; 30$ head Limousin $><P O$. Variable of research are body length, shoulder height, chest circumference and body weight. Qualitatif performance variables are colour of skin, type of head, type of face, hump, hides cattle, and horn type. Qualitative data analyzed by descriptive analysis, and quantitative data analyzed by $t$-test. The result of research showing calf qualitative performance has different in every bull. Body weight of cattle for each are $P O$ cattle $(248,36 \pm 24,89 \mathrm{~kg})$; calf from Simmental $><P O$ cattle $(257,08 \pm 27,88 \mathrm{~kg})$ and it's showing significant different $(P<0.05)$; calf from Limousin $><P O$ cattle $(252,25 \pm 32,51 \mathrm{~kg})$. The body measurment for each cattle showing variation.
\end{abstract}

Keywords : Bull, calf performance, Peranakan Ongole cattle, Central Lampung

\section{PENDAHULUAN}

Kondisi populasi dari ternak setiap tahun berubah. Laju pertumbuhan ternak cenderung lambat dan tidak sejalan dengan peningkatan permintaan daging nasional dengan laju 6-8\% pertahun (Thalib et al., 2003). Upaya yang dilakukan dalam rangka peningkatan populasi dan produksi ternak maka pemerintah telah memberikan bantuan ternak kepada para petani di daerah-daerah yang berpotensi untuk pengembangan ternak (Priyanti et al., 1988).

Sapi Ongole, merupakan keturunan dari Bos indicus yang berhasil dijinakkan di India, masukkeIndonesia padaabadke-19.Kemurnian bangsa sapi Ongole dipertahankan di pulau Sumba, sehingga disebut Sumba Ongole. Sapi Sumba Ongole tersebut disilangkan dengan cara grading up dengan sapi lokal antara lain sapi Jawa, sehingga terbentuk sapi Peranakan Ongole atau dikenal dengan sapi PO (Sumadi dan Siliwolu, 2004). Potensi sapi PO secara genetik cukup baik dalam hal adaptasi dan produktivitas. Namun belakangan ini terjadi penurunan mutu genetik ternak sapi PO yang dimanifestasikan pada turunnya berat badan dan ukuran-ukuran tubuh ternak.

Salah satu upaya yang dilakukan pemerintah Kabupaten Lampung Tengah Provinsi Lampung untuk meningkatkan mutu genetik sapi PO adalah memasukkan darah baru atau kawin silang melalui program Inseminasi Buatan (IB) menggunakan mani beku dari beberapa bangsa yaitu : Simmental dan Limousin yang di IB ke induk sapi PO. Program peningkatan mutu genetik dengan memasukkan darah baru atau kawin silang melalui IB sangat ditentukan oleh pengaruh gen pejantan dan kecocokan gen pejantan dengan kondisi lingkungan masyarakat peternak di kabupaten Lampung Tengah (Hamdani, 2013). Pada peternakan rakyat di Kabupaten Lampung Tengah, anak hasil persilangan induk sapi PO dengan beberapa pejantan lainnya banyak ditemukan di beberapa desa di Kecamatan Terbanggi Besar. Kecamatan tersebut merupakan wilayah program peningkatan produktivitas ternak melalui Inseminasi Buatan (IB) di kabupaten Lampung Tengah, hal ini didukung dengan adanya Balai Inseminasi Buatan Daerah (BIBD) di kabupaten tersebut.

Produktivitas seekor ternak dan dapat dilihat dari bobot badan dan pertambahan bobot badannya (Chamdi, 2005). Pendekatan lainnya yaitu melalui pengamatan ukuranukuran tubuh sapi yang berkorelasi erat dengan bobot badan (Hamdani et al., 2017). Hal ini sesuai dengan pendapat Hardjosubroto (1994) bahwa beberapa ukuran tubuh berkorelasi dan mengindikasikan hubungan yang erat dengan bobot badan. 
Performa kualitatif juga sangat diperlukan untuk mengetahui karakteristik sifat kegenetikan dari anak hasil persilangan induk sapi PO dengan pejantan bangsa yang lain seperti warna kulit, ada tidaknya gelambir, ada tidaknya punuk, bentuk muka dan sifat eksterior lainnya. Oleh karena itu, telah dilakukan penelitian yang bertujuan untuk menyelidiki performa sifat kualitatif dan sifat kuantitatif anak hasil persilangan sapi PO induk dengan bangsa pejantan yang berbeda di Kecamatan Terbanggi Besar Kabupaten Lampung Tengah.

\section{MATERI DAN METODE}

Penelitian ini dilaksanakan pada bulan Mei - Agustus 2018. Pengamatan sifat kualitatif dan pengukuran sifat kuantitatif dilakukan terhadap anak sapi PO dan hasil persilangan antara induk sapi PO dengan berbagai bangsa pejantan pada berumur 1 tahun. Hewan penelitian terdiri dari sapi potong yang berjumlah 90 ekor yang terdiri dari sapi PO yang berjumlah 30 ekor; sapi hasil persilangan Simmental $><\mathrm{PO}$ berjumlah 30 ekor dan sapi hasil persilangan Limousin $><\mathrm{PO}$ berjumlah 30 ekor.

Penentuan umur diketahui dari recording atau berdasarkan tampilan gigi seri permanen yaitu umur satu tahun sapi PO ditandai dengan munculnya gigi seri permanen yang berjumlah satu pasang. Metode penelitian yang digunakan adalah metode survey dengan teknik pengambilan data secara purposive sampling. Purposive sampling adalah metode pengambilan sampel yang dipilih secara cermat sehingga relevan dengan struktur penelitian, dimana pengambilan sampel dengan pengambilan sampel yang dipilih oleh penulis menurut ciri-ciri spesifik dan karakteristik tertentu (Djarwanto, 1998). Data yang digunakan adalah data primer. Peubah yang diamati dalam penelitian ini adalah : performa sifat kualitatif meliputi : warna kulit, bentuk tanduk, bentuk kepala, ada tidaknya gelambir, dan ada tidaknya punuk. Performa kuantitatif meliputi : bobot badan (BB), lingkar dada (LD), tinggi pundak (TP) dan panjang badan (PB).

\section{Analisis Data}

Data performa sifat kualitatif dianalisis menggunakan analisis deskriptif. Performa sifat kuantitatif berupa nilai rataan setiap peubah diuji dengan uji-t (Siegel, 1994).

\section{HASIL DAN PEMBAHASAN}

\section{Performa Kualitatif Sapi PO, Peranakan Simmental dan Peranakan Limousin.}

Karakteristik kualitatif dari sapi-sapi penelitian meliputi : warna kulit, ada tidaknya gelambir, ada tidaknya punuk, ada tidaknya tanduk, didasarkan pada perbedaan kualitatif diantara sapi PO dan sapi hasil persilangan Simmental $><\mathrm{PO}$ dan sapi hasil persilangan Limousin $><$ PO. Sifat kualitatif yang ada yaitu: warna rambut putih, ada gelambir, ada punuk, dan bertanduk. Sapi hasil persilangan Simmental $><$ PO meliputi warna coklat, tidak bergelambir, tidak berpunuk, tidak bertanduk. Sapi hasil persilangan Limousin $><\mathrm{PO}$ sifat kualitatifnya, coklat tua, tidak bergelambir, tidak berpunuk, tidak bertanduk. Hasil persilangan kedua bangsa berbeda akan berpengaruh pada sifat kualitatif anak hasil persilangan. Sifat kualitatif hasil persilangan dapat dilihat pada Tabel 1.

Tabel 1. Karakteristik kualitatif: warna kulit sapi PO, Sapi Peranakan Simmental dan Peranakan Limousin.

\begin{tabular}{|c|c|c|c|c|c|c|}
\hline \multirow{3}{*}{ Bangsa } & \multicolumn{6}{|c|}{ Karakteristik kualitatif } \\
\hline & \multicolumn{6}{|c|}{ Warna kulit } \\
\hline & Putih & Coklat tua & $\begin{array}{l}\text { Coklat } \\
\text { muda }\end{array}$ & $\begin{array}{l}\text { Putih } \\
\text { hitam }\end{array}$ & $\begin{array}{l}\text { Coklat } \\
\text { putih }\end{array}$ & $\begin{array}{l}\text { Putih coklat } \\
\text { hitam }\end{array}$ \\
\hline $\mathrm{PO}$ & $100 \%$ & - & - & - & - & - \\
\hline $\begin{array}{l}\text { Hasil Persilangan } \\
\text { Simmental }><\mathrm{PO}\end{array}$ & - & - & - & $29,16 \%$ & $45,83 \%$ & $25,01 \%$ \\
\hline $\begin{array}{l}\text { Hasil Persilangan } \\
\text { Limousin }><\mathrm{PO}\end{array}$ & - & $68,35 \%$ & $31,65 \%$ & - & - & - \\
\hline
\end{tabular}

Pada Tabel 1 terlihat sapi PO berwarna putih sebanyak $100 \%$, sedangkan untuk sapi hasil persilangan Simmental $><\mathrm{PO}$ dan
Limousin $><$ PO muncul keragaman warna. Pada sapi hasil persilangan Simmental $><\mathrm{PO}$ warna rambut coklat-putih sebanyak $45,83 \%$, 
putih-hitam 29,16\% dan putih-coklat-hitam sebanyak 25,01\%, sedangkan sapi hasil persilangan Peranakan Limousin $><\mathrm{PO}$ didominansi warna coklat tua sebanyak $68,35 \%$ dan coklat muda 31,65\%.

Sapi PO, sapi hasil persilangan Simmental $><\mathrm{PO}$ dan sapi hasil persilangan Limousin $><$ PO memiliki gelambir $(100 \%)$ untuk ketiga jenis sapi. Untuk sifat ada atau tidaknya punuk muncul keragaman dengan rincian, ternak sapi hasil persilangan Simmental $><\mathrm{PO}$ memiliki punuk sebanyak $20,83 \%$ dan sapi hasil persilangan Limousin $><\mathrm{PO}$ sebanyak $21,51 \%$ serta untuk sifat tanduk masing-masing $62,5 \%$ dan 64,56\%. Hal ini sesuai dengan Sulastri dan Dakhlan (2002) yang menyatakan sifat kualitatif sangat dipengaruhi oleh faktor genetik dan hampir tidak dipengaruhi oleh faktor lingkungan.

Tabel 2. Karakteristik kualitatif : gelambir punuk dan tanduk

\begin{tabular}{lccc}
\hline Bangsa Sapi & \multicolumn{3}{c}{ Karakteristik kualitatif } \\
\cline { 2 - 4 } & Gelambir & Punuk & Tanduk \\
\hline PO & $100 \%$ & $100 \%$ & $100 \%$ \\
Hasil Persilangan & $100 \%$ & $20,83 \%$ & $62,5 \%$ \\
Simmental $><\mathrm{PO}$ & $100 \%$ & $21,51 \%$ & $64,56 \%$ \\
Hasil Persilangan & & & \\
Limousin $><\mathrm{PO}$ & &
\end{tabular}

\section{Berat Sapi Umur Satu Tahun}

Berat umur satu tahun adalah berat pedet yang diukur pada saat umur 365 hari. Rataan berat umur satu tahun anak hasil persilangan induk sapi PO dengan pejantan Limousin, pejantan Simmental dan pejantan PO sendiri dapat dilihat pada Tabel 3.

Tabel 3. Berat umur satu tahun sapi PO, sapi Peranakan Simmental dan sapi Peranakan Limousin

\begin{tabular}{lccc}
\hline & Sapi PO & $\begin{array}{c}\text { Sapi Hasil Persilangan } \\
\text { Simmental }><\text { PO }\end{array}$ & $\begin{array}{c}\text { Sapi Hasil Persilangan } \\
\text { Limousin }><\text { PO }\end{array}$ \\
\hline Nilai Rata-rata (kg) & $248,36^{\mathrm{a}}$ & $257,08^{\mathrm{b}}$ & $252,25^{\mathrm{a}}$ \\
Standar deviasi & 24,89 & 27,88 & 32,51 \\
Nilai Maksimum $(\mathrm{kg})$ & 304 & 324 & 315 \\
Nilai Minimum (kg) & 178 & 203 & 202 \\
Jumlah & 30 & 30 & 30 \\
\hline
\end{tabular}

Dari Tabel 3 terlihat sapi PO, sapi hasil persilangan Simmental $><\mathrm{PO}$ dan sapi hasil persilangan Limousin $><\mathrm{PO}$ mempunyai nilai masing- masing $248,36 \pm 24,89 \mathrm{~kg}$; $257,08 \pm 27,88 \mathrm{~kg} ; 252,25 \pm 32,51 \mathrm{~kg}$. Dari data tersebut terlihat muncul keragaman bobot badan sapi umur satu tahun, hal ini karena adanya pengaruh genetik pejantan yang berbeda pada ternak tersebut. Hardjosubroto (1994) menyatakan bobot badan ternak di pengaruhi oleh genetik dan lingkungan. Hamdani et al. (2018) menyatakan lingkungan khususnya manajemen pemeliharaan sangat berperan penting dalam peningkatan bobot badan ternak.

Hasil analisis uji beda rata-rata menunjukkan berat badan umur setahun sapi hasil persilangan Simmental $><\mathrm{PO}$ menunjukkan perbedaan yang nyata dibandingkan sapi PO dan sapi hasil persilangan Limousin $><$ PO. Artinya berat badan sapi hasil persilangan dua bangsa lebih baik dibandingkan perkawinan satu bangsa. Depison (2010) menjelaskan berat badan dan pertambahan berat badan hasil persilangan pejantan Simmental dan induk sapi PO lebih baik dibandingkan hasil persilangan pejantan Limousin dan pejantan PO. Williams (1982) menyatakan persilangan sapi-sapi jenis PO dengan bangsa-bangsa sapi di daerah subtropik memiliki berat badan yang lebih baik.

Hasil penelitian ini lebih tinggi dibandingkan penelitian Depison (2010) menggunakan induk sapi Bali dengan beberapa penjantan yang salah satunya yaitu PO, Simmental dan Limousin masing-masing berat pedet yang dihasilkan pada umur 1 tahun masing-masing adalah: 148,25 $\pm 22,12 \mathrm{~kg} ; 179,21$ $26,66 \mathrm{~kg} ; 176,80 \pm 29,27 \mathrm{~kg}$. 


\section{Ukuran-ukuran tubuh}

Tabel 4. Ukuran-ukuran tubuh ternak

\begin{tabular}{lccc}
\hline \multirow{2}{*}{ Bangsa Sapi } & \multicolumn{3}{c}{ Ukuran-ukuran tubuh } \\
\cline { 2 - 4 } & $\mathrm{LD}(\mathrm{cm})$ & $\mathrm{PB}(\mathrm{cm})$ & $\mathrm{TP}(\mathrm{cm})$ \\
\hline PO & $151,43 \pm 11,13^{\mathrm{a}}$ & $110,28 \pm 10,00^{\mathrm{a}}$ & $120,37 \pm 7,71^{\mathrm{a}}$ \\
Hasil Persilangan Simental $><\mathrm{PO}$ & $155,74 \pm 21,00^{\mathrm{b}}$ & $113,00 \pm 13,20^{\mathrm{b}}$ & $124,53 \pm 11,16^{\mathrm{b}}$ \\
Hasil Persilangan Limousin $><\mathrm{PO}$ & $152,36 \pm 22,00^{\mathrm{a}}$ & $111,03 \pm 11,73^{\mathrm{a}}$ & $123,99 \pm 9,90^{\mathrm{a}}$ \\
\hline
\end{tabular}

Tabel 4 menunjukkan ukuran tubuh meliputi : lingkar dada (LD); panjang badan (PB) dan tinggi pundak (TP) hasil penelitian ini menunjukkan sapi hasil persilangan Simmental $><$ PO mempunyai nilai LD; PB; dan TP yang lebih tinggi dibandingkan dengan sapi yang lain dan hasil uji t menunjukkan adanya keragaman. Hal ini sesuai dengan pernyataan Thalib et al. (2003) yang menyatakan hasil persilanganumumnya mempunyai penampilan yang lebih baik dibandingkan bangsa tetuanya.

Hasil penelitian ini juga menunjukkan turunan yang mempunyai bobot badan tinggi juga mempunyai ukuran tubuh yang tinggi pula. Hal ini sesuai dengan pernyataan Lana et al. (1983) bahwa dimensi tubuh mempunyai korelasi positif dengan bobot badan. Selanjutnya menurut Ludy et al. (2004) bahwa penampilan seekor ternak dapat diketahui berdasarkan penampilan dari, ukuran tubuh berat lahir, dan berat badan sapi. Penampilan berat badan dan ukuran tubuh adalah penting dalam perbaikan mutu genetik ternak, karena hal ini akan membantu di dalam program seleksi (Hamdani et al., 2017).

\section{KESIMPULAN}

Anak hasil persilangan antara induk sapi PO dengan pejantan Simmental dan pejantan Limousin memiliki performa sifat kualitatif yang berbeda khususnya warna rambut, tanduk dan punuk, tetapi semua anak sapi yang diamati memiliki gelambir yang diwarisi dari induk sapi PO. Bobot badan sapi umur satu tahun hasil persilangan induk sapi PO dengan pejantan Simmental berbeda lebih tinggi daripada hasil persilangan induk sapi $\mathrm{PO}$ dengan pejantan Limousin dan sapi PO murni, tetapi antara sapi hasil persilangan $\mathrm{PO}$ dengan pejantan Limousin dengan sapi PO murni tidak berbeda, masing-masing dengan bobot badan untuk sapi PO adalah 248,36 $\pm 24,89 \mathrm{~kg}$; sapi hasil persilangan Simmental $><$ PO 257,08 $\pm 27,88$ $\mathrm{kg}$; dan sapi hasil persilangan Limousin $><\mathrm{PO}$ $252,25 \pm 32,51 \quad \mathrm{~kg}$. Ukuran-ukuran tubuh meliputi LD, PB dan TP untuk masing-masing ternak menunjukkan adanya keragaman.

\section{DAFTAR PUSTAKA}

Chamdi, A. N. 2005. Kajian Profil Sosial Ekonomi Usaha Kambing di Kecamatan Kradenan Kabupaten Grobogan. Prosiding Seminar Nasional Teknologi Peternakan dan Veteriner. Bogor 29-30 September 2003. Puslitbang Peternakan/Departemen Pertanian. Bogor.

Depison. 2010. Performans anak hasil persilangan induk sapi Bali dengan beberapa bangsa pejantan di kabupaten Batanghari Provinsi Jambi. Jurnal Agripet. 8(1): 37-41.

Djarwanto. 1998. Statistik Induktif. Edisi keempat. BPFE. Yogyakarta.

Hamdani, M. D. I. 2013. Hubungan antara Berat badan Sapi Betina PO dan sapi Persilangan pada tingkatan umur yang berbeda terhadap ukuran dan karakteristik ovariumnya. Jurnal Ilmu Peternakan Terpadu. 2(3): 79-85.

Hamdani, M. D. I., K. Adhianto, Sulastri, A. Husni, \& R. Sari. 2017. Ukuran-ukuran tubuh sapi Krui jantan dan betina di Kabupaten Pesisir Barat, Lampung. Jurnal Ilmu Ternak. 17(2): 99105.

Hamdani, M. D. I., A. Husni, \& A. Setyawan. 2018. Performa kuantitatif sapi Peranakan Ongole pascasapih di Sentra Peternakan Rakyat Maju Sejahtera Kabupaten Lampung Selatan. Jurnal Peternakan. 15(2): 68-73.

Hardjosubroto, W. 1994. Aplikasi Pemuliabiakan Ternak di Lapangan. PT. Grasindo. Jakarta.

Lana, K., Artika, \& I.M. Nitis, 1983. Pengaruh konsentrat terhadap dimensi tubuh serta korelasinya dengan berat badan sapi Bali jantan kebiri yang dibandingkan. Prosiding Pertemuan Ilmiah Ruminansia Besar P4 dan B3 Departemen Pertanian Bogor. Bogor.

Ludy, K., Kristianto, \& M. B. Nappu, 2004. Prospek pengembangan sapi potong melalui pola pengembangan sapi potong melalui penggembalaan kolektif dalam upaya swasembada daging sapi di Kalimantan Timur, Lokakarya Nasional Sapi Potong. Balai Pengkajian Teknologi Pertanian Kalimantan Timur.

Priyanti, A., T. Sudjana, S. W. Handayani, \& P. J. Ludgate. 1988. Karakteristik peternak berpenampilan tatalaksana tinggi dan rendah dalam usaha ternak domba/kambing di Kabupaten Bogor, Jawa Barat. Prosiding 
Pertemuan Ilmiah Ruminansia. Jilid 2. Pusat Penelitian dan Pengembangan Peternakan. Badan Penelitian dan Pengembangan Pertanian. Departemen Pertanian. Bogor. Hal 7-11.

Siegel, S. 1994. Statistik Non Parametrik untuk Ilmuilmu Sosial. PT. Gramedia Pustaka Utama, Jakarta.

Sulastri, \& Dakhlan. 2002. Dasar Pemuliaan Ternak. Buku Ajar Jurusan Peternakan UNILA : Bandar Lampung.

Sumadi, \& Siliwolu. 2004. Penelitian mutu genetik sapi Ongole dan Brahman di kabupaten Sumba Timur, Nusa Tenggara Timur. Lokakarya Nasional sapi Potong, Jakarta: 31-41.
Thalib, C. K. Entwistle, A. Siregar, S. Budiarti-Turner, \& D. Lindsay. 2003. Survey of Population and Production Dynamics Of Bali Cattle and Exixting Breeding Program In Indonesia. In: K. Entwistle and D.R. Lindsay (eds), Strategies to Improve Bali Cattle in Eastern Indonesia. ACIAR Proc. No 10: 3-9.

Williams, I. H. 1982. Growth and Energy. Dalam: A Course Manual in Nutrition and Growth. H. L. Davies (Ed.). Australian Vice-Chancellors' Committee. AUIDP, Hedges and Bell Pty Ltd. Melbourne. 